\title{
Clinical manifestations and molecular epidemiology of five cases of diarrhoea in children associated with Vibrio metschnikovii in Arequipa, Peru
}

\author{
A. DALSGAARD, A. ALARCON*, C. F. LANATA $\dagger$, T. JENSEN, H. J. HANSEN, F. DELGADO*, \\ A. I. GIL†, M. E. PENNY† and D. TAYLOR $\ddagger$
}

Department of Veterinary Microbiology, Royal Veterinary and Agricultural University, Frederiksberg, Denmark, * Laboratorio de Microbiologia, Hospital General Honorio Delgado, Ministerio de Salud, Arequipa, $\dagger$ Instituto de Investigacion Nutricional, Lima and $\ddagger$ Departments of Microbiology and Medical Ecology, United States Naval Medical Research Institute Detachment, Lima, Peru

\begin{abstract}
In April 1994, Vibrio metschnikovii was isolated from five infants with watery diarrhoea in Arequipa, Peru, as part of a passive cholera surveillance system. The children ranged in age from 11 to 20 months and had acute diarrhoea, with two cases showing moderate dehydration. Two children also had traces of blood in liquid stool. The children were seen at two different hospitals, and no evidence of a common source of infection was found. No additional $V$. metschnikovii isolates were identified in the remaining surveillance period that covered the rest of 1994 and 1995. However, stool samples were not screened for enteric pathogens other than vibrios. $V$. metschnikovii strains isolated from stool samples produced opaque and translucent colonies on agar plates, suggesting capsular material. All isolates were resistant to ampicillin, erythromycin and streptomycin. Plasmid analysis revealed a common $200-\mathrm{kb}$ plasmid in isolates from all cases and an additional $2.7-\mathrm{kb}$ plasmid in three of the isolates. Ribotyping of each isolate after restriction with $B g l l$ and HindIII endonucleases demonstrated identical ribotyping patterns. The cases reported suggest that $V$. metschnikovii may be associated with diarrhoea in man by mechanisms so far unknown.
\end{abstract}

\section{Introduction}

Vibrio spp. are natural inhabitants of aquatic environments, and most human infections are acquired by exposure to such environments or to foods derived from them [1]. An increasing number of Vibrio spp. is recognised to be pathogenic to man, with Vibrio cholerae being the most important [1]. V. metschnikovii was first described in 1888 [2]. The bacterium is unique among human pathogenic Vibrio spp. as it is oxidase negative and does not reduce nitrate to nitrite $[1,3]$.

$V$. metschnikovii is often isolated from the environment but rarely from human clinical specimens [1,3]. Strains of $V$. metschnikovii not associated with man have been isolated from river water, estuaries, sewage,

Received 21 Feb. 1996; revised version accepted 18 May 1996.

Corresponding author: Dr A. Dalsgaard. cockles, oysters, lobsters, fowl [3] and a bird that died from a cholera-like illness [4]. Human-derived strains of the species have been isolated from a patient with peritonitis and an inflamed gall bladder [5], two cases of septicaemia [6] and in pure culture from the faeces of a 60-year-old woman with diarrhoea [7].

Limited data have been published concerning possible virulence factors of $V$. metschnikovii but it is not known if the species produces typical enterotoxins, such as Escherichia coli heat-stable enterotoxin or cholera enterotoxin. Although $V$. metschnikovii has been isolated from animal as well as human intestines, there is little evidence to suggest that the species causes enteritis in man [1,3]. However, Miyake et al. [7] characterised a $V$. metschnikovii strain isolated from an episode of diarrhoea and demonstrated the production of a cytolysin that lysed erythrocytes and caused fluid accumulation in mice [7].

Among the increasing number of molecular based typing methods applied in epidemiological studies of bacterial infections, ribotyping has proved to be a 
valuable technique in the study of several pathogens, including $V$. cholerae [8-10].

This study reports the clinical manifestations of five cases of diarrhoea in children in Arequipa, Peru, possibly associated with $V$. metschnikovii. Isolates were characterised phenotypically and by plasmid profiling and ribotyping.

\section{Materials and methods}

\section{Clinical specimens and antibiotic susceptibility}

A passive cholera surveillance scheme was initiated in February 1994 in two Ministry of Health hospitals in the city of Arequipa, the second largest city in Peru. This was in preparation for a vaccine field trial to evaluate the efficacy of an oral killed whole-cell recombinant $\mathrm{B}$ toxin subunit $V$. cholerae vaccine.

A stool specimen or rectal swab was obtained by trained study nurses from each diarrhoeal patient seen in the emergency rooms of the two hospitals $24 \mathrm{~h} /$ day, 7 days/week. Samples were inoculated into Cary Blair transport media and transported at ambient temperature to the microbiology laboratory where they were processed $24-48 \mathrm{~h}$ after obtaining the initial sample. Thiosulphate-Citrate-Bile salt-Sucrose (TCBS) Agar (Difco) was inoculated with the stool sample directly and after enrichment for $6-8 \mathrm{~h}$ in alkaline-peptonewater ( $\mathrm{pH} 8.6)$ and incubated aerobically at $37^{\circ} \mathrm{C}$ for $24 \mathrm{~h}$. Suspected $V$. cholerae (yellow colonies) were characterised by standard biochemical reactions [11] and agglutinated with polyvalent and monovalent $\mathrm{O} 1$ antiserum (Denka Seiken, Tokyo, Japan). In the period from 9 April to 18 April 1994, stool samples obtained from five children produced growth of yellow colonies on TCBS, that did not agglutinate with polyvalent $\mathrm{O} 1$ antiserum. By means of characterisation and identification criteria previously recommended for human pathogenic Vibrio spp., the isolates were identified as $V$. metschnikovii [3]. All media used to identify $V$. metschnikovii contained $\mathrm{NaCl} 1 \%$. In a single episode (case no. 4) $V$. metschnikovii was isolated from two different stool samples (isolates AR004a and AR004b). In addition, the API 20E assay (bioMerieux, France) was used to identify isolates suspected to be $V$. metschnikovii following the manufacturer's recommendation for the identification of Vibrio spp. No other pathogenic Vibrio spp. were isolated from stool samples of the five patients. However, stool samples were not screened for other enteric pathogens. $V$. metschnikovii strain NCTC 8443, previously isolated from a diseased fowl, was included as a reference strain in subsequent studies [4].

The six $V$. metschnikovii isolates were tested for susceptibility to 10 antibacterial agents by disk diffusion on Diagnostic Sensitivity Test Agar (Oxoid) supplemented with calf blood 5\%, with disks (NeoSensitabs, Rosco, Denmark) containing ( $\mu \mathrm{g} / \mathrm{disk})$ : ampicillin 30, cephalothin 66, chloramphenicol (low) 10, chloramphenicol (high) 60, erythromycin 78, kanamycin 100 , nalidixic acid 130 , polymyxin B 50 $\mathrm{U}$, streptomycin 60 , tetracycline (low) 10 , tetracycline (high) 80 , trimethoprim/sulphamethoxazole $5.2 / 240$ and the vibriostatic agent (O/129) 150. Antibiotic susceptibility tests were done according to the manufacturers' instructions and isolates were recorded as sensitive, intermediate or resistant [12].

\section{Conjugal transfer assay}

One recipient strain, Escherichia coli $\mathrm{K}-12\left(185^{\mathrm{r}}\right)$, was selected for mating experiments and each of the five $V$. metschnikovii isolates was examined studied for conjugal transfer. Mating mixtures were plated on nonselective L Agar (Difco) at $37^{\circ} \mathrm{C}$ for $4-5 \mathrm{~h}$, after which growth was harvested, diluted and inoculated on to MacConkey Agar (Difco) supplemented with nalidixic acid $50 \mathrm{mg} / \mathrm{L}$ and appropriate concentrations of selected drugs.

\section{Plasmid profiling and ribotyping}

The strains were grown aerobically in Brain Heart Infusion Broth (BHI; Difco) for $5 \mathrm{~h}$ at $37^{\circ} \mathrm{C}$. Plasmid preparation was by the method of Kado and Liu [13], modified by incubating the cells at $\mathrm{pH} 12.75$ for $30 \mathrm{~min}$ at $65^{\circ} \mathrm{C}$ during the lysis step. Electrophoresis and visualisation of plasmids was done essentially as described previously [14]. Estimation of molecular sizes of each plasmid was achieved by the use of several reference plasmids from $E$. coli V517 (eight plasmids ranging from 54 to $2.0 \mathrm{~kb}$ ) [15] and $E$. coli 39R 861 (four plasmids ranging from 147 to $6.9 \mathrm{~kb}$ ) [16]. Plasmid DNA was extracted at least three times from all isolates.

Total bacterial DNA for ribotyping was extracted by the method of Murray and Thompson [17]. Based on previous studies, in which the restriction endonucleases $B g l \mathrm{I}$ and HindIII (Promega, Madison, WI, USA) were used to discriminate isolates of $V$. cholerae and $V$. anguillarum, respectively, these enzymes were used to digest DNA of the $V$. metschnikovii isolates $[8,10,18]$. Ribotyping was performed by the procedure described by Dalsgaard et al. [10] with digoxigenin-labelled $16 \mathrm{~S}$ and $23 \mathrm{~S}$ rRNA probes. A 1-kb mol.wt standard (Gibco BRL, Gaithersburg, MD, USA) was used as a mol.wt marker.

\section{Results and discussion}

This study reports what is possibly the first outbreak of diarrhoea associated with $V$. metschnikovii. Five cases of $V$. metschnikovii infection were reported in 1994 
from two hospitals in Arequipa, Peru, as part of a surveillance system for cholera. The cases were reported within a 10-day period, although the patients lived in distant communities in the outskirts of Arequipa. In addition, the Social Security Hospital in Arequipa was included in the surveillance. Hence, all major hospitals in Arequipa, which diarrhoeal patients requiring medical attention in an emergency room could attend, were included in the surveillance with stool samples obtained from all individuals, with no age restriction. No further $V$. metschnikovii isolates were identified in the remaining surveillance period that covered the rest of 1994 and 1995 (Fig. 1).

A summary of the clinical data of the five cases of $V$. metschnikovii infection is presented in Table 1 . The patients ranged in aged from 11 to 20 months and included one female patient. Three patients experienced vomiting within $24 \mathrm{~h}$ following admission to hospital and three patients showed elevated temperature (cases 1, 3 and 5). Cases 1 and 2 were hospitalised and received intravenous rehydration. All patients showed symptoms diagnosed as acute diarrhoeal disease, including frequent passage of liquid or semi-liquid stools (Table 1). However, two patients (cases 1 and 5) produced liquid diarrhoea with traces of blood. Unfortunately, screening of stool samples for other enteric pathogens was not part of the surveillance program in Arequipa. Hence, it is not known whether a second pathogen could have been the primary cause of the diarrhoea. However, since the last case was reported on 18 April 1994, no further cases of diarrhoea associated with $V$. metschnikovii infection have been reported (Fig. 1).

Previously, only one case of diarrhoea associated with $V$. metschnikovii has been reported when a 60 -year-old woman with diabetes mellitus and a hepatoma developed diarrhoea $[1,7]$. In the present study it was not possible to elucidate the transmission of $V$. metschnikovii from the patient data and no evidence of a common source of infection was found. However, as $V$. metschnikovii is often found in water and seafood, such samples may have been vehicles of transmission [3]. The search for new cases of diarrhoea associated with $V$. metschnikovii is being continued in a passive surveillance system in order to carry out a casecontrol study and to identify potential risk factors.

The biochemical reactions of the five clinical isolates of $V$. metschnikovii are shown in Table 2. All isolates showed identical characteristics, including negative oxidase and nitrate reduction tests, which are unique reactions for $V$. metschnikovii compared with other pathogenic Vibrio spp. [1]. The isolates gave negative reactions in the following tests: Voges-Proskauer, citrate and indole production. Although few $V$. metschnikovii isolates have been characterised pre-

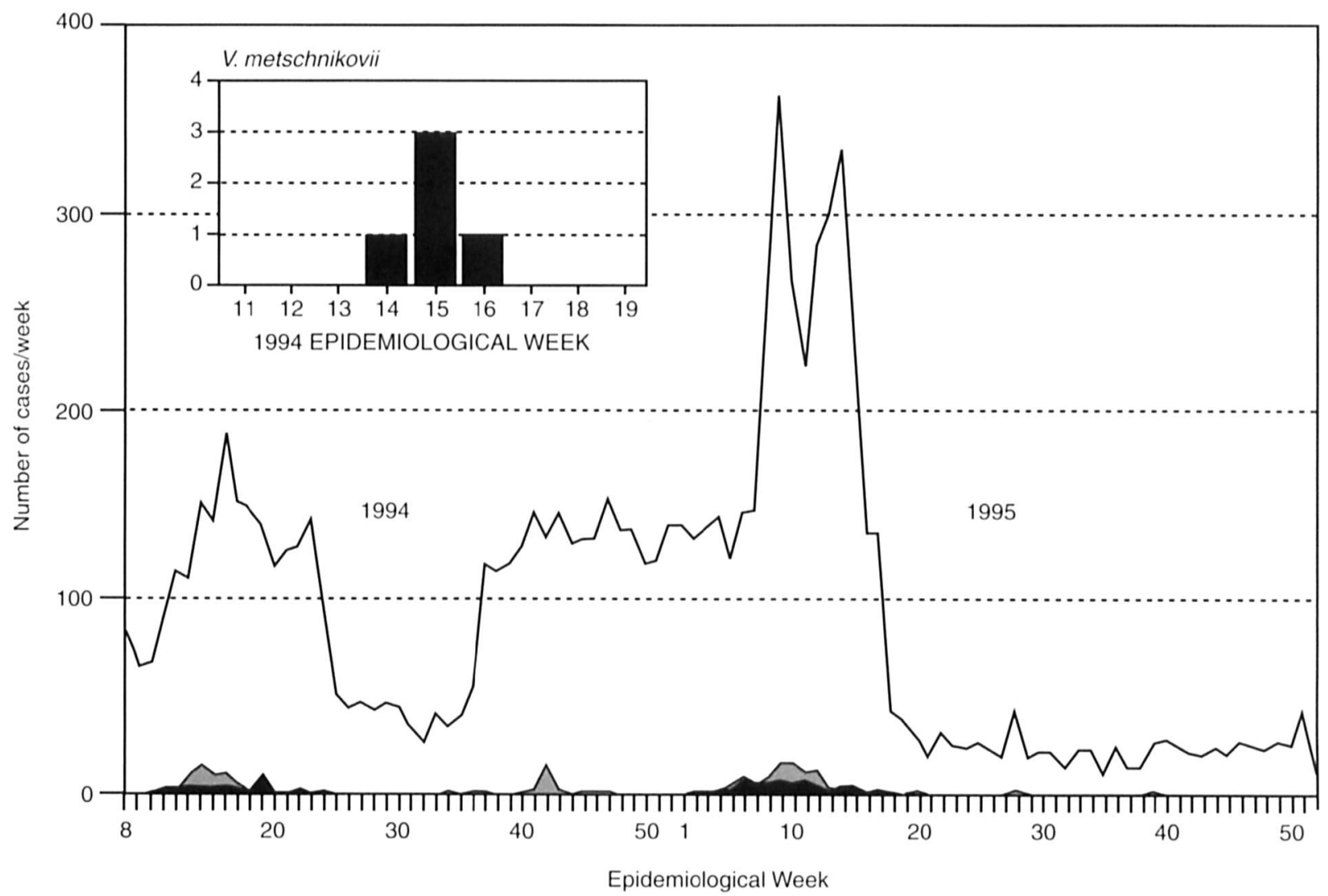

Fig. 1. Number of diarrhoea cases that were cultured at three hospital emergency rooms per epidemiological week and type of Vibrio identified in Arequipa, Peru, 1994-1995. - , diarrhoea cases; $\mathbf{0}$, V. cholerae; $\mathbf{\mathbf { m }}$, all vibrios. 
Table 1. Summary of clinical data of five Peruvian children with diarrhoea associated with $V$. metschnikovii

\begin{tabular}{|c|c|c|c|c|c|c|}
\hline $\begin{array}{l}\text { Strain no./ } \\
\text { case no. }\end{array}$ & Date of sample & $\begin{array}{l}\text { Age/ } \\
\text { sex* }\end{array}$ & $\begin{array}{c}\text { Number of } \\
\text { vomiting } \dagger \text { episodes }\end{array}$ & $\begin{array}{l}\text { Bloody } \\
\text { stool }\end{array}$ & $\begin{array}{l}\text { Degree of } \\
\text { dehydration } \ddagger\end{array}$ & Clinical diagnosis \\
\hline $\mathrm{AR} 002 / 1$ & 9 April 1994 & $15 / \mathrm{M}$ & 5 & Yes & Moderate & $\begin{array}{l}\text { Acute diarrhoeal disease } \\
\text { Dysentery }\end{array}$ \\
\hline AR003/2 & 18 April 1994 & $12 / \mathrm{M}$ & 4 & No & Moderate & Acute diarrhoeal disease \\
\hline AR004/3 & 10 April 1994 & $12 / \mathrm{M}$ & 2 & No & None & Acute diarrhoeal disease \\
\hline AR005/4 & 10 April 1994 & $20 / \mathrm{M}$ & 0 & No & None & Acute diarrhoeal disease \\
\hline AR006/5 & 14 April 1994 & $11 / F$ & 0 & Yes & None & $\begin{array}{l}\text { Acute diarrhoeal disease } \\
\text { Dysentery }\end{array}$ \\
\hline
\end{tabular}

*Age is indicated as number of months; M, male; F, female.

†Within $24 \mathrm{~h}$ following admission to the hospital.

$\ddagger$ Degree of dehydration by World Health Organization standards.

Table 2. Phenotypic characteristics of the five $V$. metschnikovii isolates from children with diarrhoea

\begin{tabular}{|c|c|}
\hline Test & $\begin{array}{c}\text { Number of isolates } \\
\text { positive }\end{array}$ \\
\hline Oxidase (Kovacs) & 0 \\
\hline Catalase & 5 \\
\hline Nitrate reduction & 0 \\
\hline Motility $\left(37^{\circ} \mathrm{C}\right)$ & 5 \\
\hline Aerobic/anaerobic growth & 5 \\
\hline Voges-Proskauer & 0 \\
\hline Gelatin hydrolysis & 5 \\
\hline DNAase & 5 \\
\hline Urea hydrolysis & 0 \\
\hline Hydrogen sulphide & 0 \\
\hline Arginine dihydrolase & 5 \\
\hline Lysine decarboxylase & 0 \\
\hline Ornithine decarboxylase & 0 \\
\hline Citrate (Simmons) & 0 \\
\hline Indole production & 0 \\
\hline $\mathrm{ONPG}$ & 5 \\
\hline Sensitivity to $\mathrm{O} / 129(150 \mu \mathrm{g})$ & 5 \\
\hline Haemolysis & 5 \\
\hline \multicolumn{2}{|l|}{ Growth in nutrient broth with } \\
\hline $\mathrm{NaCl} 0 \%$ & 0 \\
\hline $\mathrm{NaCl} 3 \%$ & 0 \\
\hline $\mathrm{NaCl} 6 \%$ & 5 \\
\hline $\mathrm{NaCl} 7 \%$ & 5 \\
\hline $\mathrm{NaCl} 8 \%$ & 5 \\
\hline $\mathrm{NaCl} 10 \%$ & 5 \\
\hline $\mathrm{NaCl} 12 \%$ & 5 \\
\hline \multicolumn{2}{|l|}{ D-Glucose } \\
\hline Acid & 5 \\
\hline Gas & 0 \\
\hline Inositol & 5 \\
\hline Maltose & 5 \\
\hline Sucrose & 5 \\
\hline Salicin & 0 \\
\hline Cellobiose & 0 \\
\hline Swarming & 0 \\
\hline TCBS* & 5 \\
\hline
\end{tabular}

ONPG, $o$-nitrophenyl- $\beta$-D-galactopyranoside.

${ }^{*}$ Growth on TCBS.

viously, variations were reported in the results of the citrate test and in the ability to produce indole, whereas a high prevalence of the isolates tested showed a positive reaction in the Voges-Proskauer test [1-3]. As reported in a previous study of two clinical $V$. metschnikovii isolates, a double zone of haemolysis surrounding individual colonies and discolouration of blood cells in the area of confluent growth were observed for all isolates [6]. The reference strain NCTC 8443 demonstrated some different phenotypic characteristics when compared with the clinical isolates, which is in agreement with an earlier study of $V$. metschnikovii strains in which the reference strain was less versatile and unable to grow on TCBS [3]. Culture collection strains are often subcultured over many years and may have changed phenotypically and genotypically [3]. As growth of $V$. metschnikovii on TCBS may be reduced, additional media should be used for the isolation of this species [1].

During the characterisation of $V$. metschnikovii an interesting phenomenon was observed. When cultures were plated on to Tryptic-soy-casein agar (Difco), a mixture of opaque and translucent colonies of each clinical isolate was observed, whereas strain NCTC 8443 produced translucent colonies only (Fig. 2). In studies of $V$. vulnificus, a similar variation in colony morphology was observed [19]. It is well established that opaque cells of $V$. vulnificus, which are capsulate, are virulent for mice, resistant to the bactericidal activity of human serum and can utilise transferriniron for growth. In contrast, translucent cells are noncapsulate or have decreased capsular material, are avirulent, serum sensitive and cannot grow in ironlimited media, even in the presence of iron-bound transferrin [20,21]. However, the importance of capsular material in the pathogenicity of $V$. metschnikovii remains to be elucidated.

In the API 20E system two 7-digit profiles, 3007320 and 3007120 , were shown for the clinical isolates reaching identification scores of 0.98 and 0.96 , respectively, which suggest $V$. metschnikovii as the most likely taxon. However, when the API $20 \mathrm{E}$ assay was repeated in another laboratory, two different 7 digit profiles were produced, 1002220 and 3002220 , neither of which suggests $V$. metschnikovii as a likely taxon. Thus, the variation in results obtained with the API $20 \mathrm{E}$ assay indicates that the assay may be inadequate for the identification of $V$. metschnikovii.

The clinical isolates all showed resistance to ampicillin, erythromycin and streptomycin, whereas the reference strain was susceptible to all antimicrobial agents tested. Isolate AR002 also exhibited intermediate resistance to polymyxin $\mathrm{B}$, trimethoprim/sulpha- 


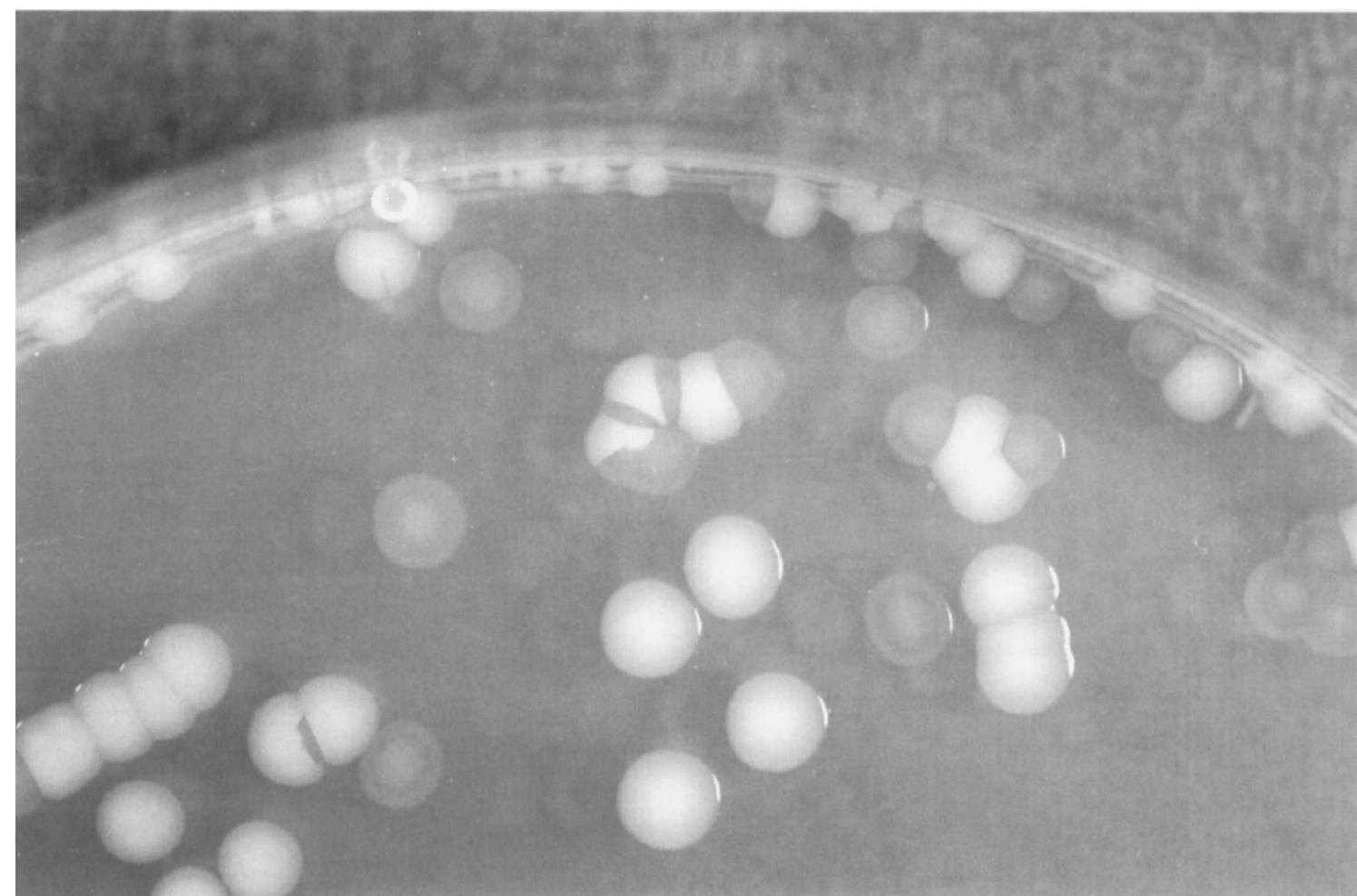

Fig. 2. Opaque and translucent colonies of $V$. metschnikovii.

methoxazole and nalidixic acid. Lee et al. [3] reported $V$. metschnikovii as highly suspectible to several antimicrobial agents tested. Therefore, it is interesting that the plasmid analysis revealed a large plasmid

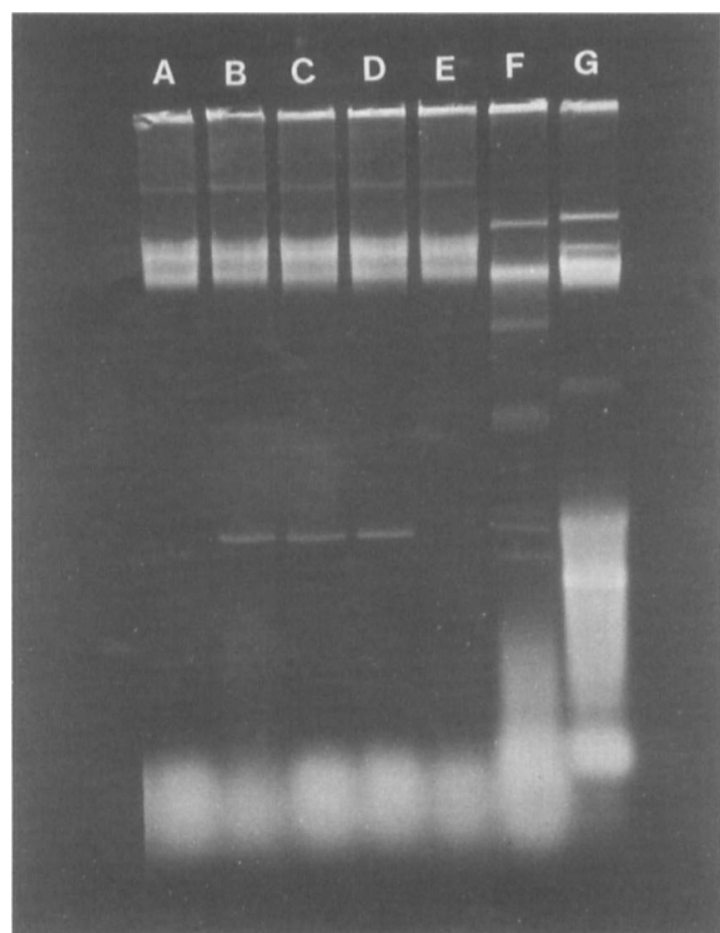

Fig. 3. Plasmid profiles of $V$. metschnikovii. Lanes: A, strain AR002; B, strain AR003; C, strain AR004a; D, strain AR005; E, strain AR006; F, E. coli V517 (eight plasmids ranging from 54 to $2.0 \mathrm{~kb}$ ); G, E. coli 39R 861 (four plasmids ranging from 147 to $6.9 \mathrm{~kb}$ ). (c. $200 \mathrm{~kb}$ ) harboured by all clinical isolates, whereas the reference strain did not possess any plasmids (Fig. 3). In addition, strains AR003, AR004 and AR005 contained a $2.7-\mathrm{kb}$ plasmid. Previous studies of clinical isolates of $V$. metschnikovii did not determine the plasmid content $[6,7]$.

Of the five isolates studied in mating experiments, AR002 and AR006 yielded exconjugants on MacConkey agar plates containing nalidixic acid and ampicillin. However, following subculture on non-selective agar and plasmid analysis none of the exconjugants contained plasmids, and each isolate was found to be sensitive to ampicillin as demonstrated by disk diffusion. It is likely that plasmid DNA was transferred, although exconjugants may have lost any transient plasmid DNA because of subculture on non-selective agar or in non-selective enrichment broth. No exconjugants were found on MacConkey agar plates containing nalidixic acid and erythromycin or on plates containing nalidixic acid and streptomycin. The importance of the $200-\mathrm{kb}$ plasmid requires further investigation.

The results of ribotyping with the restriction endonucleases BglI and HindIII are shown in Fig. 4a and b, respectively. The clinical isolates showed identical $B g l \mathrm{I}$ ribotypes with nine DNA fragments ranging from 5.5 to $13 \mathrm{~kb}$. Identical ribotypes were also obtained with HindIII showing 11 DNA fragments ranging from 0.5 to $4 \mathrm{~kb}$. Strain NCTC 8443 showed $B g l \mathrm{I}$ and HindIII ribotypes which differed by several fragments when compared with the ribotypes of the clinical 


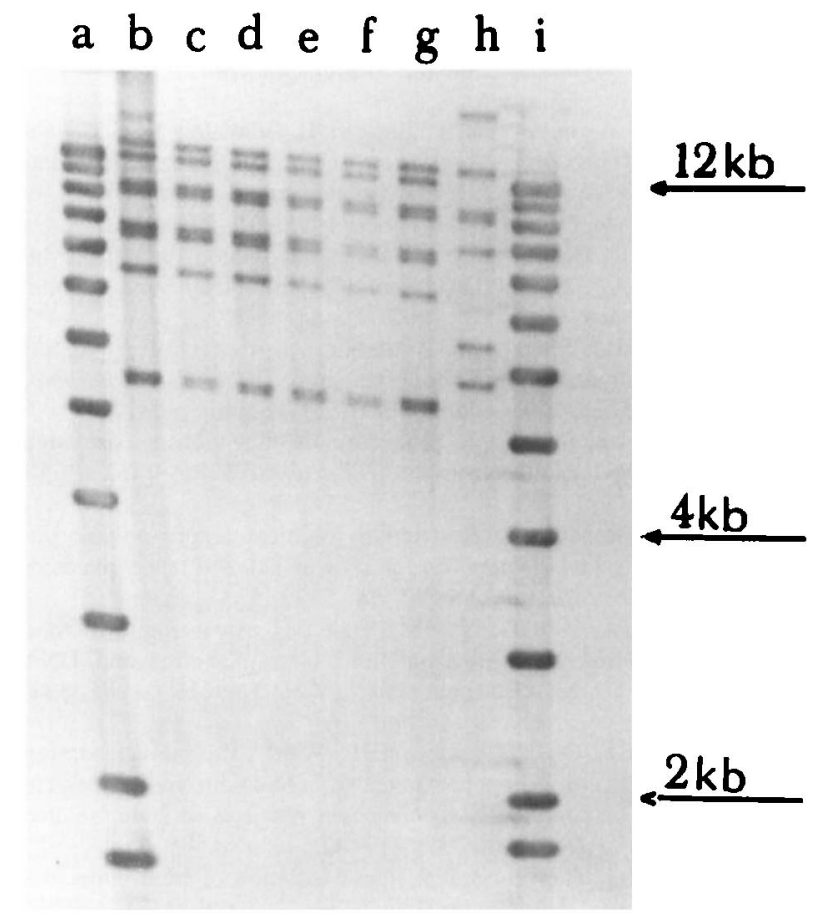

\section{$a b$ c d e f g h i}

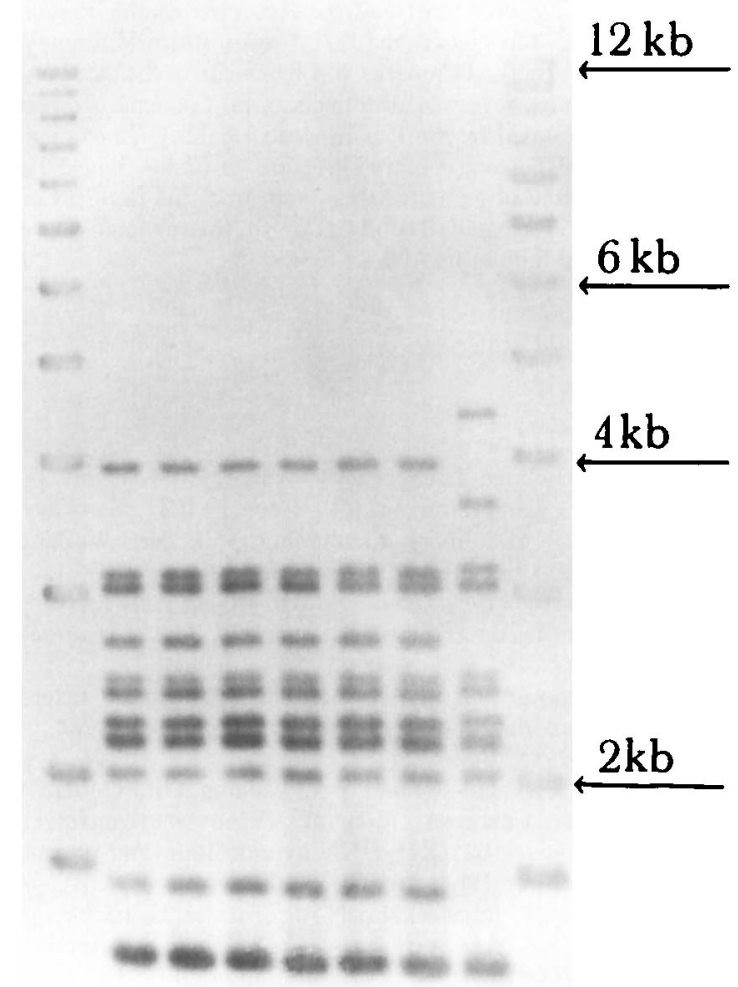

Fig. 4. a, $B g l$ I ribotypes of $V$. metschnikovii isolates from children with diarrhoea in Arequipa, Peru. Lanes: a, 1-kb mol.wt standard; b, strain AR002, ribotype MB1; c, strain AR003, ribotype MB1; d, strain AR004a, ribotype MB1, e, strain AR004b, ribotype MB1; f, strain AR005, ribotype MB1; g, strain AR006, ribotype MB1; h, strain NCTC 8443, ribotype MB2; i, 1-kb mol. wt standard. b. HindllI ribotypes of $V$. metschnikovii isolates from children with diarrhoea in Arequipa, Peru. Lanes: a, 1-kb mol.wt standard; b, strain AR002, ribotype MH1; c, strain AR003, ribotype MH1; d, strain AR004a, ribotype $\mathrm{MHl}$; e, strain AR004b, ribotype $\mathrm{MH1}$; f, strain AR005, ribotype MH1; g, strain AR006, ribotype $\mathrm{MH} 1 ;$ h, strain NCTC 8443 , ribotype $\mathrm{MH} 2$; i, 1-kb mol.wt standard.

isolates (Fig. 4a and b). Thus, the ribotyping results produced with two different restriction endonucleases support the results of the antibiotic susceptibility testing and plasmid analyses indicating that a single clone of $V$. metschnikovii was associated with the five cases of diarrhoea.

Previous ribotyping studies of Vibrio spp. with the restriction endonucleases $B g l \mathrm{I}$ and HindIII have demonstrated a high discriminatory power of the two enzymes, and have shown a high degree of heterogeneity among environmental and clinical isolates typed $[9,10,18]$. Thus, if $V$. metschnikovii was not associated with the diarrhoea cases, it is likely that the five isolates would have shown different ribotypes. However, additional $V$. metschnikovii strains and restriction endonucleases should be typed and evaluated before the most suitable enzyme for ribotyping can be determined.

Few studies have been carried out to investigate the pathogenicity of $V$. metschnikovii. However, the double zone of haemolysis exhibited by each isolate suggests that a cytolysin or a haemolysin may be an important virulence factor. Miyake et al. [7] purified and characterised a cytolysin produced by a $V$. metschnikovii isolate from the faeces of a patient with diarrhoea. This heat-labile extracellular cytolysin which had a mol.wt of 50000 , lysed erythrocytes from several animal species and showed no immunological similarities with other haemolysins of pathogenic vibrios [7]. Furthermore, the cytolysin caused fluid accumulation in the intestines of infant mice and increased the vascular permeability of rabbit skin. Similar activities were also observed in the culture supernate of the $V$. metschnikovii isolate and were completely neutralised by anti-cytolysin antibody raised against the purified cytolysin, indicating that the cytolysin may act as an enterotoxin [7]. However, further studies are needed to determine the importance of the cytolysin and other possible virulence determinants, including the production of capsular material. If further studies suggest that $V$. metschnikovii is pathogenic for man, only volunteer studies may finally prove its pathogenicity.

In conclusion, this study provides the first evidence that $V$. metschnikovii strains may have diarrhoeagenic potential for man through as yet unknown mechanism(s) and may cause outbreaks. 
We are grateful to Ines Pineda, Betzabe Alarcon and Hector Verastegui for their help in establishing the surveillance system, to the study nurses, hospital staff and the Arequipa Health Region for their support; to O. Rasmussen and D. J. Brown, Royal Veterinary and Agricultural University, Denmark, for technical assistance and $M$. Chadfield for critical review of the manuscript. Financial support for the study was provided by the Panamerican Health Organization and by the Diarrhoeal Disease Control Programme of the World Health Organization. A.D. was supported by a grant from the Danish Council for Development Research, Danida (Danish International Development Assistance), fellowship 104.8/553.

\section{References}

1. Kelly MT, Hickman-Brenner FW, Farmer JJ. Vibrio. In: Balows A, Hausler WJ, Herrmann KL, Isenberg HD, Shadomy HJ (eds) Manual of clinical microbiology, 5th edn. Washington, DC, American Society for Microbiology. 1991: 384-395.

2. Gamalèia MN. Vibrio metschnikovii (n. sp.) et ses rapports avec le microbe du choléra asiatique. Ann Inst Pasteur (Paris) 1888; 2: $482-488$

3. Lee JV, Donovan TJ, Furniss AL. Characterization, taxonomy, and emended description of Vibrio metschnikovii. Int $J$ Syst Bacteriol 1978; 28: 99-111.

4. Farmer JJ, Hickman-Brenner FW, Fanning GR, Gordon CM, Brenner DJ. Characterization of Vibrio metschnikovii and Vibrio gazogenes by DNA-DNA hybridization and phenotype. $J$ Clin Microbiol 1988; 26: 1993-2000.

5. Jean-Jacques W, Rajashekaraiah KR, Farmer JJ, Hickman FW, Morris JG, Kallick CA. Vibrio metschnikovii bacteremia in a patient with cholecystitis. J Clin Microbiol 1981; 14: 711-712.

6. Hansen W, Freney J, Benyagoub H, Letouzey M-N, Gigi J, Wauters G. Severe human infections caused by Vibrio metschnikovii. J Clin Microbiol 1993; 31: 2529-2530.

7. Miyake M, Honda T, Miwatani T. Purification and characterization of Vibrio metschnikovii cytolysin. Infect Immun 1988; 56: $954-960$.

8. Popovic T, Bopp CA, Olsvik $\emptyset$, Wachsmuth K. Epidemiologic application of a standardized ribotype scheme for Vibrio cholerae O1. J Clin Microbiol 1993; 31: 2474-2482.

9. Dalsgaard A, Serichantalergs O, Pitarangsi C, Echeverria P.
Molecular characterization and antibiotic susceptibility patterns of Vibrio cholerae non-O1. Epidemiol Infect 1995; 114 51-63.

10. Dalsgaard A, Echeverria P, Larsen JL, Siebeling R, Serichantalergs $\mathrm{O}$, Huss $\mathrm{HH}$. Application of ribotyping for differentiating Vibrio cholerae non-O1 isolates from shrimp farms in Thailand. Appl Environ Microbiol 1995; 61: 245-251.

11. Sakazaki R. Bacteriology of vibrio and related organisms. In Barua D, Greenough WB (eds) Cholera. New York, Plenum Medical Book Company. 1992: 37-55.

12. Ericsson HM, Sherris JC. Antibiotic sensitivity testing. Report of an international collaborative study. Acta Path Microbiol Scand B Microbiol Immunol 1971; 217 Suppl.

13. Kado CI, Liu S-T. Rapid procedure for detection and isolation of large and small plasmids. J Bacteriol 1981; 145: 13651373.

14. Olsen JE, Larsen JL. Restriction fragment length polymorphism of the Vibrio anguillarum serovar $\mathrm{Ol}$ virulence plasmid. Appl Environ Microbiol 1990; 56: 3130-3132.

15. Rochelle PA, Fry JC, Day MJ, Bale MJ. An accurate method for estimating sizes of small and large plasmids and DNA fragments by gel electrophoresis. J Gen Microbiol 1985; 132: $53-59$.

16. Threlfall EJ, Rowe B, Ferguson JL, Ward LR. Characterization of plasmids conferring resistance to gentamicin and apramycin in strains of Salmonella typhimurium phage type 204c isolated in Britain. $J$ Hyg 1986; 97: 419-426.

17. Murray MG, Thompson WF. Rapid isolation of high molecular weight plant DNA. Nucleic Acids Res 1980; 8: 4321-4325.

18. Olsen JE, Larsen JL. Ribotypes and plasmid contents of Vibrio anguillarum strains in relation to serovar. Appl Environ Microbiol 1993; 59: 3863-3870.

19. Kreger A, DeChatelet L, Shirley P. Interaction of Vibrio vulnificus with human polymorphonuclear leukocytes: association of virulence with resistance to phagocytosis. $J$ Infect Dis 1981; 144: 244-248.

20. Simpson LM, White VK, Zane SF, Oliver JD. Correlation between virulence and colony morphology in Vibrio vulnificus. Infect Immun 1987; 55: 269-272.

21. Zakaria-Meehan Z, Massad G, Simpson LM, Travis JC, Oliver JD. Ability of Vibrio vulnificus to obtain iron from hemoglobin-haptoglobin complexes. Infect Immun 1988; 56: $275-277$. 